REVIEW

\title{
Melanin-based colour polymorphism responding to climate change
}

\author{
ALEXANDRE ROULIN \\ Department of Ecology and Evolution, University of Lausanne, Building Biophore, Lausanne 1015, Switzerland
}

\begin{abstract}
Climate warming leads to a decrease in biodiversity. Organisms can deal with the new prevailing environmental conditions by one of two main routes, namely evolving new genetic adaptations or through phenotypic plasticity to modify behaviour and physiology. Melanin-based colouration has important functions in animals including a role in camouflage and thermoregulation, protection against UV-radiation and pathogens and, furthermore, genes involved in melanogenesis can pleiotropically regulate behaviour and physiology. In this article, I review the current evidence that differently coloured individuals are differentially sensitive to climate change. Predicting which of dark or pale colour variants (or morphs) will be more penalized by climate change will depend on the adaptive function of melanism in each species as well as how the degree of colouration covaries with behaviour and physiology. For instance, because climate change leads to a rise in temperature and UV-radiation and dark colouration plays a role in UV-protection, dark individuals may be less affected from global warming, if this phenomenon implies more solar radiation particularly in habitats of pale individuals. In contrast, as desertification increases, pale colouration may expand in those regions, whereas dark colourations may expand in regions where humidity is predicted to increase. Dark colouration may be also indirectly selected by climate warming because genes involved in the production of melanin pigments confer resistance to a number of stressful factors including those associated with climate warming. Furthermore, darker melanic individuals are commonly more aggressive than paler conspecifics, and hence they may better cope with competitive interactions due to invading species that expand their range in northern latitudes and at higher altitudes. To conclude, melanin may be a major component involved in adaptation to climate warming, and hence in animal populations melanin-based colouration is likely to change as an evolutionary or plastic response to climate warming.
\end{abstract}

Keywords: climate change, colour polymorphism, melanin, melanocortin, phenoloxidase, pleiotropy

Received 18 December 2013 and accepted 26 March 2014

\section{Introduction}

Climate change is predicted to accelerate evolutionary processes. Rapid modifications in climate can be detrimental to natural populations because their habitats are disappearing and most organisms have little time to evolve new adaptations or pre-existing adaptations did not have the time to spread in populations (Quintero \& Wiens, 2013). Lack of genetic variation may increase the risk of extinction, since the probability that at least one genotype is adapted to the new prevailing environmental conditions is lower in species with lower genetic diversity (Thompson et al., 2012). This phenomenon should be pronounced when climate change modifies environmental conditions to which species are specifically adapted and when these species are not phenotypically plastic enough to modify their physiology and

Correspondence: Alexandre Roulin, tel. + 4169241 89, fax + 4169241 65, e-mail: Alexandre.Roulin@unil.ch behaviour accordingly. Furthermore, organisms often face new competitive species that expand their range in regions where the climate is becoming warmer (Thomas \& Lennon, 1999; Levy, 2004) at northern latitudes and higher altitudes (IPPC, 2007). As a result, many species already disappeared or are threatened leading to a decline in biodiversity (Parmesan, 2006). If studying how climate will change in the mid- to long term is the focus of huge research efforts, predicting which species or individuals are particularly vulnerable is another challenge.

Climate change is predicted to influence the pace of evolutionary processes. Although the assumption that climate warming exerts strong directional selection on organisms is well accepted, evidence for the evolution of novel genetic adaptations has received fewer empirical supports (Jump \& Peñuelas, 2005; Gienapp et al., 2008). However, the effects of climate change on evolutionary processes may not be straightforward to predict. If climate change sets unfavourable conditions, the 
expression of the genetic potential for any given trait may be constrained (Hoffmann \& Merilä, 1999). Under such conditions, the relative contribution of environmental components to total phenotypic variance may increase, hindering evolutionary change. For instance, climate change may heavily interfere with sexual selection processes (Spottiswoode \& Saino, 2010). This is the case because it may influence the cost of the expression of sexual signals relevant to mate choice and therefore disrupt the reliability of the expression of epigamic signals as signals of the underlying genetic quality. Finally, because climate warming modifies the environment to which animals are adapted, it may affect the equilibrium frequency at which colour-specific reproductive strategies achieve equal fitness (e.g. Sinervo \& Lively, 1996; Tuttle, 2003).

Environmental changes due to climate warming are so rapid that to persist organisms have to quickly evolve new phenotypes that are adapted to the new environmental conditions, an outcome that is more likely to happen if these organisms are sufficiently variable at genes implicated in response to stressful factors induced by climate change (Franks \& Hoffmann, 2012). Here, I discuss the possibility that the degree of genetic variation is positively associated with resilience to climate change (e.g. Pearman et al., 2010). I consider the specific case of melanin-based colour polymorphism, a phenotypic marker of genetic adaptations (Roulin, 2004; McKinnon \& Pierotti, 2010) with the specific prediction that colour polymorphic species may be more resistant to global warming than colour monomorphic species. In polymorphic species, some morphs may be more resistant to climate change and a key issue is whether the same morph (e.g. dark rather than pale coloured morph) is more resilient to stress across organisms. This may be the case since most colour polymorphisms are due to differential deposition of melanin pigments on the integument, pigments that have very similar effects on thermoregulation, protection against pathogens and resistance to abrasion of the integument across animals. Furthermore, the genetics of melanogenesis is very well conserved and the few genes that have pleiotropic effects on a number of other phenotypes have very similar effects across vertebrates (Sugumaran, 2002; Ducrest et al., 2008).

In this review, I first discuss scenarios about how global warming could differentially affect dark and pale melanic morphs. I then review the current scientific evidence that global change indeed differentially affects dark and pale melanic individuals. The main message of this review is that melanin-based colouration is associated with evolutionary and plastic responses to global warming. Even if dark colourations may often have a selective advantage over pale colourations under global warming, there are situations where the opposite pattern is predicted.

\section{How global warming can differentially affect dark and pale melanic morphs}

I discuss scenarios about how climate warming may generate fitness differences between colour morphs. This discussion shows that climate warming acts as a new selective agent that favours dark over pale individuals in many situations.

\section{$U V$-radiation}

Climate warming induces an increase in ultraviolet (UV) radiation in regions where the stratospheric ozone is depleted (Manney et al., 2011) and where cloudiness has not increased (Min et al., 2011). Ectotherms (and to a lower extent endotherms) rely on solar radiation to warm up with black colouration absorbing more solar energy, thereby reducing the metabolic cost of homeothermy (Heppner, 1970; Walsberg et al., 1978; ClusellaTrullas et al., 2008). Differently coloured individuals often exploit alternative ecological niches (Galeotti \& Rubolini, 2004; Roulin, 2004; Stoletzki \& Schierwater, 2005; Castella et al., 2013) such as in reptiles in which dark melanic individuals often reside in shady habitats with less UV-radiation (Tanaka, 2007; Kearney et al., 2009; Karpestam et al., 2012). In this case, paler ectotherms may be more affected by global warming because of the increase in UV-radiations. However, if pale and dark individuals exploit the same habitat, it is unclear which of them will suffer more from the increase in UV-radiations. On the one hand, dark individuals may suffer from overheating and on the other hand melanin pigments can confer a protection against UV-radiations (Andersen, 2011). This protective role of melanin explains why humans are darker in regions where UVradiation levels are higher (Jablonski \& Chaplin, 2000). Animals for which melanin plays such a protective function may therefore become darker coloured in regions, where UV-radiations are increasing due to climate warming (Häkkinen et al., 2002; Rautio \& Korhola, 2002; Garcia et al., 2004; Gao et al., 2010; Manney et al., 2011), as an outcome of selection favouring genes encoding a darker colouration and from tanning induced by UVradiations. This change would be adaptive because in human skin cancer is predicted to rise due to the higher exposure to UV-radiations (Diffey, 2004).

\section{Humidity and thermoregulation}

Climate warming leads to a change in humidity and temperature in a number of regions (Min et al., 2011; 
D'Odorico et al., 2013). According to the Gloger's rule, animals are usually darker coloured in more humid environments and paler in drier habitats (Zink \& Remsen, 1986; Kamilar \& Bradley, 2011; Singaravelan et al., 2013). The frequency of light coloured individuals may therefore increase in regions where deserts are expanding and darker coloured in regions where humidity is predicted to increase (Min et al., 2011). The Gloger's rule is based on the assumption that melanin pigments or colouration itself confers fitness benefits (Burtt \& Ichida, 2004). The situation is more complex if we consider that genes implicated in the production of melanin pigments have numerous pleiotropic effects on the resistance to various stressful factors as observed in vertebrates (Ducrest et al., 2008; Roulin \& Ducrest, 2011; Emaresi et al., 2013). Indeed, ambient temperature profoundly affects physiological processes (Walters et al., 2012) and hence climate warming may be experienced as physiologically stressful. Resistance conferred by pleiotropic genes involved in melanogenesis may therefore give a selective advantage to dark over pale coloured individuals.

\section{Pathogens}

Invertebrates lack adaptive immunity and use nonspecific immune defence mechanisms to resist pathogen invasions. This includes, among other molecules, melanin to encapsulate parasites (which does not appear to be the case in vertebrates) and enzymes of the phenoloxydase cascade involved in the melanin-producing cascade and immunity (Armitage \& Siva-Jothy, 2005). This explains why in insects darker melanic individuals are usually more resistant to pathogens (Fedorka et al., 2013a,b). As climate warming is associated with an increase in infectious diseases in many ecosystems (e.g. Harvell et al., 2009; Altizer et al., 2013), melanic individuals may have a selective advantage. For instance, in a cricket heat induces an increased activity of phenoloxidase probably to enhance immunocompetence (Adamo \& Lovett, 2011 but see Seppala \& Jokela, 2011 and Karl et al., 2011), and phenoloxidase activity is higher in dark than pale individuals (Bailey, 2011). Therefore, melanic individuals may have a selective advantage under the threat of climate warming due to an increase in pathogens.

\section{Increased interspecific competition}

Climate warming offers new areas to be colonized by competitive species. For instance, many species could expand their range at northern latitudes and higher altitudes where climate is becoming warmer (Thomas \& Lennon, 1999; Levy, 2004; IPPC, 2007). Therefore, species that evolved adaptations to live at northern and alpine climates are faced with new competitors. The ability to compete against new invading species is related to colouration (Brazill-Boast et al., 2013) and because darker melanic individuals are commonly more aggressive and competitive than paler conspecifics (Senar \& Domenach, 2011), probably as a consequence of the pleiotropic effects of melanogenic genes (Ducrest et al., 2008), darker coloured individuals may better cope with the new competitive environment than their paler conspecifics. Furthermore, in a comparative study, it has been shown that darker species show more circulating testosterone (Bókony et al., 2008) and hence darker melanic species may also better cope with the threat of invading species that expand their distributional range due to climate warming.

\section{Evidence for melanic-specific responses to global warming}

I review here the current evidence about the colourspecific responses to climate warming (Anderson et al., 2012).

\section{Genetic adaptations}

Climate change acts as a selective factor that can promote the evolution of new adaptations or the spread of pre-existing adaptations initially found at low frequencies, although evidences for such a mechanism are still limited (e.g. Gienapp et al., 2008; Karell et al., 2011). Because melanin-based colouration plays a role in diverse functions as diverse as camouflage, thermoregulation or integument protection against biophysical agents but also because genes implicated in melanogenesis pleiotropically regulate many other physiological and behavioural functions (Ducrest et al., 2008; Fedorka et al., 2013a,b), the frequency of melanin-based colour morphs may change as a consequence of direct selection exerted by climate warming on colouration itself or indirect selection exerted on phenotypic traits that are genetically correlated with colouration.

I surveyed the literature about temporal changes in the frequency of colour morphs accounted to climate warming. A first study performed in Italian scops owls (Otus scops) reported a strong increase in the frequency of darker reddish melanic individuals between 1870 and 2007 among skin specimens preserved in natural history museums (Galeotti et al., 2009). This increase in frequency was maximal, when three years before specimen collection the climate was warmer and wetter. This observation suggests that dark reddish birds born in warmer/wetter years have higher fecundity and/or survival than pale individuals, a finding that is 
consistent with studies in other owls. In the screech owl (Otus asio), dark reddish individuals have a selective advantage in warm years and pale reddish birds in cold years (Mosher \& Henny, 1976); additionally, in Italy dark and pale reddish tawny owls were found dead more often in cool-dry and warm-wet years, respectively (Galeotti \& Cesaris, 1996). These temperatureand morph-specific advantages have a physiological basis as shown by measuring oxygen consumption under controlled ambient temperatures (Mosher \& Henny, 1976 and see also Roulin et al., 2005).

These patterns of colour-specific adaptations to climate may apply to many species because on the northern hemisphere, owl species are on average darker reddish near the equator than polewards where they are paler (Roulin et al., 2011). Because climate changes to a larger extent at high than low latitudes (IPPC, 2007), dark reddish owls may expand their range northwards more than pale reddish owls may expand their range southwards. Thus, in colour polymorphic owls the frequency of the dark reddish morph may currently increase in frequency at the expanse of pale reddish morph. Accordingly, using data collected in northern Europe (Finland) between 1981 and 2009 dark reddish tawny owls increased drastically in frequency because winters became warmer and in turn the survival of dark reddish owls increased disproportionally compared to pale reddish conspecifics (Karell et al., 2011).

Altogether, these studies indicate that darker melanic owls have currently a selective advantage over paler melanic owls. However, because dark reddish colouration is due to a higher deposition of both pheomelanin and eumelanin pigments (Gasparini et al., 2009), it remains unclear which of the two pigments are favoured under climate warming. This is an important issue because the hormones that trigger the production of pheomelanin (ASIP and possibly AGRP) and eumelanin $(\alpha-\mathrm{MSH})$ by binding melanocortin-1-receptors (MC1R) have different physiological effects when binding the four other melanocortin receptors (MC2-5Rs) (Ducrest et al., 2008). Thus, the key question is whether climate warming favours eumelanic individuals, and thus potentially those that produce more $\alpha-\mathrm{MSH}$, or pheomelanic individuals producing more ASIP and/or AGRP. Suitable organisms to discriminate between these two alternative scenarios should display a colour trait that varies from dark eumelanic (black) to dark pheomelanic (brown). A recent study tackled this question in pied flycatchers (Ficedula hypoleuca) (Sirkiä et al., 2013) in which plumage colouration varies continuously from black to brown. These authors found that the proportion of brown males strongly decreased in Finland from 1954 to 2008. The probable causes are a decline of brown immigrants coming from Central
Europe where flycatcher populations strongly declined due to climate change and also colour- and temperature-specific metabolic rates (Sirkiä et al., 2010).

\section{Colour-specific dispersal}

If dispersal itself can be affected by climate warming (Massot et al., 2008), it is instrumental to individuals for tracking their shifting habitat explaining why many species extended their range polewards and to higher altitudes (Wilson et al., 2005). The first reaction animals can adopt in a hostile environment is to flee or look for refuges to buffer the new extreme conditions (Garcia et al., 2004), a property that can be colour-specific (Mateos-Gonzalez \& Senar, 2012; Van den Brink et al., 2012; Roulin, 2013; Saino et al., 2014). Immigration from a source population where the conditions are beyond the individual tolerance limits may explain a change in the genetic constitution of a sink population. In species showing geographic colour variation, differential immigration between populations should generate in sink populations an increase in the frequency of the colour variants usually found in source populations. Furthermore, if the conditions met in the sink population are particularly favourable to immigrants, their colour morph may thrive. If climate warming causes a decrease in the size of the source or sink populations, this will affect the colour composition of the sink population because the proportion of immigrants to residents will be modified, as found in Finnish pied flycatchers (Ficedula hypoleuca) (Sirkiä et al., 2013) and the common lizard (Lacerta vivipara) (Lepetz et al., 2009).

\section{Evolutionary implications of global warming on melanin-based colouration}

In a number of animals, evidences are accumulating that darker coloured individuals have a selective advantage over paler conspecifics under the new prevailing environmental conditions caused by climate warming (Fig. 1). However, there are situations under which pale individuals are favoured. Variation in the degree of colour variation may therefore decrease in animal populations and in turn genes encoding for a specific colouration may become fixed, a phenomenon that is not restricted to colouration (Rubidge et al., 2012). Because episodes of strong directional selection due to changes in climate occurred many times in history (e.g. D'Andrea et al., 2011), the equilibrium frequency at which colour variants achieve the same fitness may only rarely persist during very long periods of time. For instance, when climate becomes warmer or colder, nonadapted colour variants may become 


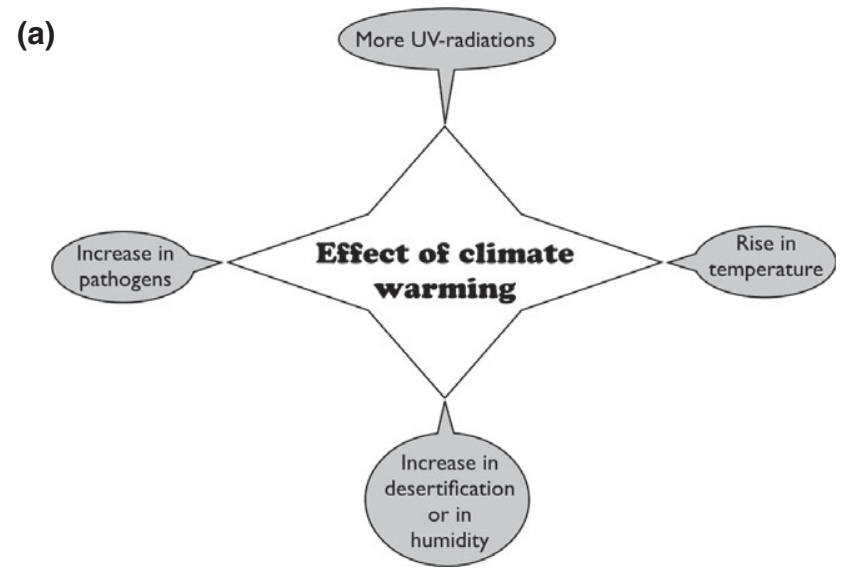

(b)

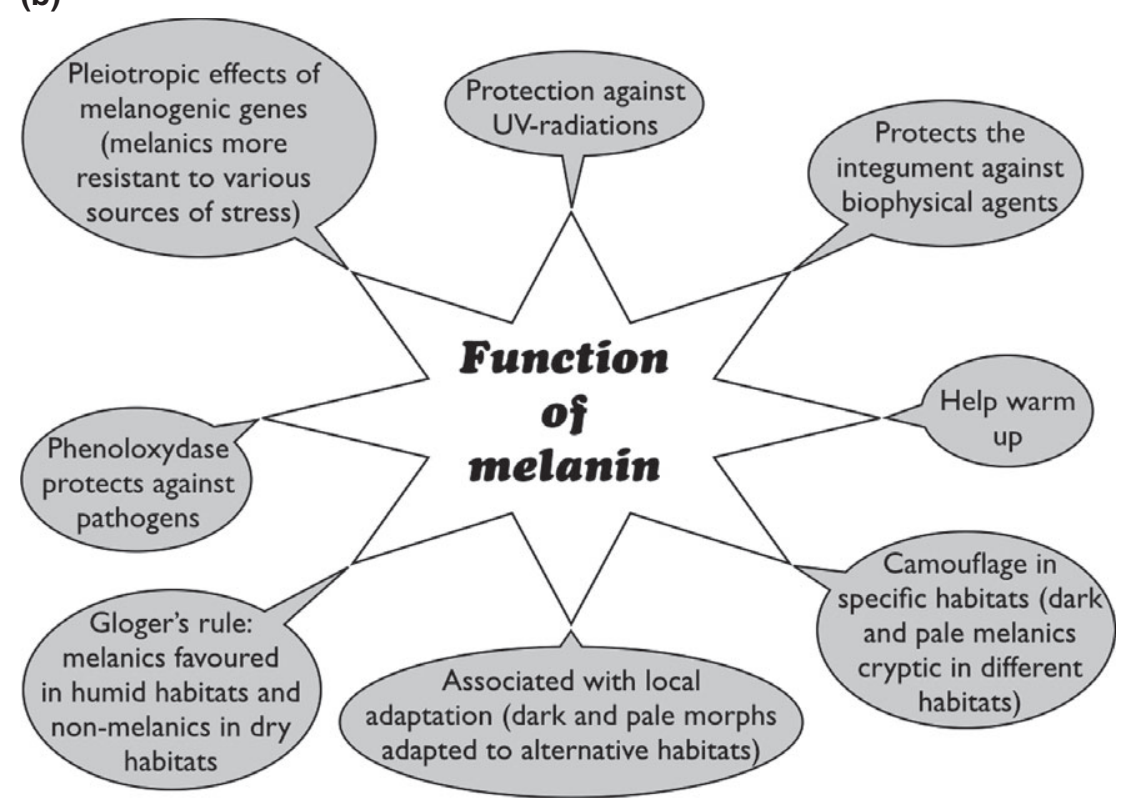

Fig. 1 Summary of the effects of climate warming on ecological factors (a) and adaptive function of melanin-based colouration that could participate in the resilience to climate warming $(b)$.

extinct. This may explain, at least in part, why colour polymorphic species are so rare in nature (e.g. $3 \%$ in birds, Galeotti et al., 2003) perhaps because the most adapted morph persists implying that polymorphic species rapidly evolve towards monomorphism. Indeed, colour morphs are often adapted to alternative environmental conditions, implying that polymorphic species can exploit a larger diversity of habitats (Galeotti \& Rubolini, 2004; Forsman \& Aberg, 2008) and expand their distributional range over larger areas than monomorphic species (Forsman \& Aberg, 2008). Since climate warming is more pronounced in some areas than in others (IPPC, 2007), alternative morphs may become more abundant in different parts of the species range potentially promoting intraspecific geographic variation and possibly allopatric speciation (Hugall \& Stuart-Fox, 2012). However, because climate warming is particularly pronounced in regions that are usually cold (such as those at high latitude and altitude), global change should lead to an increase in environmental homogeneity at very large geographic scales. For this reason, we can predict that the degree of colour variation will decrease not only within populations but also among populations because morphs adapted to warm climates should be selected over larger geographic areas.

\section{Conclusion}

This review emphasizes the fact that climate warming can differentially affect different species but also that individuals from a given population are not all similarly affected. Climate warming can therefore be viewed as a new selective factor that can select some 
specific variants or morphs that are more resilient to this new source of stress. A number of research programmes can be proposed (Box 1) as the study of melanin-based colouration can be viewed as one example among many other traits that may confer resistance to climate change.

\section{Box 1}

A number of studies can be proposed about the potential effect of climate change on melanin-based colouration:

- Assess whether the frequency of melanin-based colour morphs changes as a result of climate warming. This can be done using data from longterm monitoring of free-living populations or by measuring specimens preserved in natural history museums and collected over more than 1.5 century (e.g. Galeotti et al., 2009).

- Assess whether the temporal change in the frequency of genes underlying variation in melaninbased colouration is associated with climate change.

- Measure the effect of climate change on the heritable and environmental components of melaninbased colouration. Mean colouration in a population can indeed change as a result of microevolution (change in the frequency of the genes underlying colouration) and/or because colouration is phenotypically plastic (e.g. skin colour in human is sensitive to UV radiation).

- Measure gene expression levels/phenoloxydase activity in relation to temperature or UV-radiation to estimate the potential effect of climate warming on melanogenesis.

- Determine whether species that declined in abundance or even disappeared due to climate change are differently coloured compared to species for which population sizes are stable or even increased.

\section{Acknowledgements}

I am grateful to Sylvain Dubey, Nicola Saino, Yann Bourgeois, and three anonymous referees for useful comments.

\section{References}

Adamo SA, Lovett MME (2011) Some like it hot: the effects of climate change on reproduction, immune function and disease resistance in the cricket Gryllus texensis. Journal of Experimental Biology, 214, 1197-2004.

Altizer S, Ostfeld RS, Johnson PTJ, Kutz S, Harvell CD (2013) Climate change and infectious diseases: from evidence to a predictive framework. Science, 341, 514-519.
Andersen LK (2011) Global climate change and its dermatological diseases. International Journal of Dermatology, 50, 601-603.

Anderson JT, Panetta AM, Mitchell-Olds T (2012) Evolutionary and ecological responses to anthropogenic climate change. Plant Physiology, 160, 1728-1740.

Armitage SAO, Siva-Jothy MT (2005) Immune function responds to selection for cuticular colour in Tenebrio molitor. Heredity, 94, 650-656.

Bailey NW (2011) A test of the relationship between cuticular melanism and immune function in wild-caught Mormon crickets. Physiological Entomology, 36, 155-164.

Bókony V, Garamszegi LZ, Hirschenhauser K, Liker A (2008) Testosterone and melanin-based black plumage coloration: a comparative study. Behavioral Ecology and Sociobiology, 62, 1229-1238.

Brazill-Boast J, Griffith SC, Pryke SR (2013) Morph-dependent resource acquisition and fitness in a polymorphic bird. Evolutionary Ecology, 27, 1189-1198.

Burtt EH, Ichida JM (2004) Gloger's rule, feather-degrading bacteria, and color variation among song sparrows. The Condor, 106, 681-686.

Castella B, Golay J, Monney J-C, Golay P, Mebert K, Dubey S (2013) Melanism, body condition and elevational distribution in the asp viper. Journal of Zoology, 290, 273 280

Clusella-Trullas S, Terblanche JS, Blackburn TM, Chown SL (2008) Testing the thermal melanism hypothesis: a macrophysiological approach. Functional Ecology, 22, 232-238.

D'Andrea WJ, Huang Y, Fritz SC, Anderson NJ (2011) Abrupt Holocene climate change as an important factor for human migration in West Greenland. Proceedings of the National Academy of Sciences, 108, 9765-9769.

Diffey B (2004) Climate change, ozone depletion and the impact on ultraviolet exposure of human skin. Physics in Medicine and Biology, 49, R1-R11.

D'Odorico P, Bhattachan A, Davis KF, Ravi S, Runyan CW (2013) Global desertification: drivers and feedbacks. Advances in Water Resources, 51, 326-344.

Ducrest A-L, Keller L, Roulin A (2008) Pleiotropy in the melanocortin system, coloration and behavioural syndromes. Trends in Ecology and Evolution, 23, 502-510.

Emaresi G, Ducrest A-L, Bize P, Richter H, Simon C, Roulin A (2013) Pleiotropy in the melanocortin system: expression levels of this system are associated with melanogenesis and pigmentation in the tawny owl (Strix aluco). Molecular Ecology, 22, 4915-4930.

Fedorka KM, Copeland EK, Winterhalter WE (2013a) Seasonality influences cuticle melanisation and immune defense in a cricket: support for a temperature-dependent immune investment hypothesis in insects. Journal of Experimental Biology, 216, 4005-4010.

Fedorka KM, Lee V, Winterhalter WE (2013b) Thermal environment shapes cuticle melanism and melanin-based immunity in the ground cricket. Evolutionary Ecology, 27, 521-531.

Forsman A, Aberg V (2008) Variable coloration is associated with more northerly geographic range limits and larger range sizes in North American lizards and snakes. Evolutionary Ecology Research, 10, 1025-1036.

Franks SJ, Hoffmann AA (2012) Genetics of climate change adaptation. Annual Review of Genetics, 46, 185-208.

Galeotti P, Cesaris C (1996) Rufous and grey colour morphs in the Italian tawny owl: geographic and environmental influences. Journal of Avian Biology, 27, 15-20.

Galeotti P, Rubolini D (2004) The niche variation hypothesis and the evolution of colour polymorphism in birds: a comparative study of owls, nightjars and raptors. Biological Journal of the Linnean Society, 82, 237-248.

Galeotti P, Rubolini D, Dunn PO, Fasola M (2003) Colour polymorphism in birds: causes and functions. Journal of Evolutionary Biology, 16, 635-646.

Galeotti P, Rubolini D, Sacchi R, Fasola M (2009) Global changes and animal phenotypic responses: melanin-based plumage redness of scops owls increase with temperature and rainfall during the last century. Biology Letters, 5, 532-534.

Gao W, Schmoldt DL, Slusser JR (2010) UV Radiation in Global Climate Change, Measurements, Modelling and Effects on Ecosystems. Tsinghua University Press, Beijing.

Garcia TS, Stacy J, Sih A (2004) Larval salamander response to UV radiation and predation risk: color change and microhabitat use. Ecological Applications, 14, 1055 1064.

Gasparini J, Piault R, Bize P, Roulin A (2009) Synergistic and antagonistic interactions between different branches of the immune system is related to melaninbased coloration in nestling tawny owls. Journal of Evolutionary Biology, 22, 2348-2353.

Gienapp P, Teplistsky C, Alho JS, Mills JA, Merilä J (2008) Climate change and evolution: disentangling environmental and genetic responses. Molecular Ecology, 17, 167-178.

Häkkinen J, Vehniäinen E, Ylönen O et al. (2002) The effects of increasing UV-B radiation on pigmentation growth and survival of coregonid embryos and larvae. Environmental Biology of Fishes, 64, 451-459. 
Harvell D, Altizer S, Cattadori IM, Harrington L, Weil E (2009) Climate change and wildlife diseases: when does the host matter the most? Ecology, 90, 912-920.

Heppner F (1970) The metabolic significance of differential absorption of radiant energy by black and white birds. The Condor, 72, 50-59.

Hoffmann AA, Merilä J (1999) Heritable variation and evolution under favourable and unfavourable conditions. Trends in Ecology and Evolution, 14, 96-101.

Hugall AF, Stuart-Fox D (2012) Accelerated speciation in colour-polymorphic birds. Nature, 485, 631-634.

IPPC (2007) Climate Change 2007: The Physical Science Basis. Working group I Contribution to the fourth assessment report of the IPPC. Cambridge University Press, Cambridge.

Jablonski NG, Chaplin G (2000) The evolution of human skin coloration. Journal of Human Evolution, 39, 57-106.

Jump AS, Peñuelas J (2005) Running to stand still: adaptation and the response of plants to rapid climate change. Ecology Letters, 8, 1010-1020.

Kamilar JM, Bradley BJ (2011) Interspecific variation in primate coat colour supports Gloger's rule. Journal of Biogeography, 38, 2270-2277.

Karell P, Ahola K, Karstinen T, Valkama J, Brommer JE (2011) Climate change drives microevolution in a wild bird. Nature Communications, 2, 208.

Karl I, Stoks R, De Block M, Janowitz SA, Fischer K (2011) Temperature extremes and butterfly fitness: conflicting evidence from life history and immune function. Global Change Biology, 17, 676-687.

Karpestam E, Wennersten L, Forsman A (2012) Matching habitat choice by experimentally mismatched phenotypes. Evolutionary Ecology, 26, 893-907.

Kearney M, Shine R, Porter W (2009) The potential for behavioural thermoregulation to buffer 'cold-blooded' animals against climate warming. Proceedings of the National Academy of Sciences, 106, 3835-3840.

Lepetz V, Massot M, Chaine A, Clobert J (2009) Climate warming and the evolution of morphotypes in a reptile. Global Change Biology, 15, 454-466.

Levy S (2004) Native incursions: avian range expansions imperil threatened species BioScience, 54, 94-99.

Manney GL, Santee ML, Rex M et al. (2011) Unprecedented Arctic ozone loss in 2011. Nature, 478, 469-475.

Massot M, Clobert J, Ferrière R (2008) Climate warming, dispersal inhibition and extinction risk. Global Change Biology, 14, 461-469.

Mateos-Gonzalez F, Senar JC (2012) Melanin-based trait predicts individual exploratory behaviour in siskins, Carduelis spinus. Behavioral Ecology and Sociobiology, 83, 229-232.

McKinnon JS, Pierotti MER (2010) Colour polymorphism and correlated characters genetic mechanisms and evolution. Molecular Ecology, 19, 5101-5125.

Min S-K, Zhang X, Zwiers FW, Hegerl GC (2011) Human contribution to moreintense precipitation extremes. Nature, 470, 378-381.

Mosher JA, Henny CJ (1976) Thermal adaptiveness of plumage color in screech owls. The Auk, 93, 614-619.

Parmesan C (2006) Ecological and evolutionary responses to recent climate change. Annual Review of Ecology and Systematics, 37, 637-669.

Pearman PB, D'Amen M, Graham CH, Thuiller W, Zimmermann NE (2010) Withintaxon niche structure: niche conservatism, divergence and predicted effects of climate change. Ecography, 33, 990-1003.

Quintero I, Wiens JJ (2013) Rates of projected climate change dramatically exceed past rates of climatic niche evolution among vertebrate species. Ecology Letters, 16, 1095-1103.

Rautio M, Korhola A (2002) UV-induced pigmentation in subarctic Daphnia. Limnology and Oceanography, 47, 295-299.

Roulin A (2004) The evolution, maintenance and adaptive function of genetic colour polymorphism in birds. Biological Reviews, 79, 815-848.

Roulin A (2013) Ring recoveries of dead birds confirm that darker pheomelanic barn owls disperse longer distances. Journal of Ornithology, 154, 871-874.
Roulin A, Ducrest A-L (2011) Association between melanism, physiology and behaviour: a role for the melanocortin system. European Journal of Pharmacology, 660, 226 233.

Roulin A, Bize P, Tzaud N, Bianchi M, Ravussin P-A, Christe P (2005) Oxygen consumption in offspring tawny owls is associated with colour morph of foster mother. Journal of Ornithology, 146, 390-394.

Roulin A, Burri R, Antoniazza S (2011) Owl melanin-based plumage redness is more frequent near than away from the equator: implications on the effect of climate change on biodiversity. Biological Journal of the Linnean Society, 102, 573-582.

Rubidge EM, Patton JL, Lim M, Burton AC, Brashares JS, Moritz C (2012) Climateinduced range contraction drives genetic erosion in an alpine mammal. Nature Climate Change, 2, 285-288.

Saino N, Romano M, Scandolara C et al. (2014) Brownish, small and lousy barn swallows have greater natal dispersal propensity. Animal Behaviour, 87, 137-146.

Senar JC, Domenach J (2011) Sex-specific aggression and sex ratio in wintering finch flocks: serins and siskins differ. Acta Ethologica, 14, 7-11.

Seppala O, Jokela J (2011) Immune defence under extreme ambient temperature. Biology Letters, 7, 119-122.

Sinervo B, Lively CM (1996) The rock-paper-scissors game the evolution of alternative male strategies. Nature, 380, 240-243.

Singaravelan N, Raz S, Tzur S et al. (2013) Adaptation of pelage color and pigment variations in Israeli subterranean blind mole rats. Spalax ehrenbergi. PLOS ONE, 8 , e69346.

Sirkiä PM, Virolainen M, Laaksonen T (2010) Melanin coloration has temperaturedependent effect on breeding performance that may maintain phenotypic variation in a passerine bird. Journal of Evolutionary Biology, 23, 2385-2396.

Sirkiä PM, Virolainen M, Lehikoinen M, Laaksonen T (2013) Fluctuating selection and immigration as determinants of the phenotypic composition of a population. Oecologia, 173, 305-317.

Spottiswoode CN, Saino N (2010) Sexual selection and climate change. In: Effects of Climate Change on Birds (eds Møller AP, Wolfgang F, Berthold P), pp. 169-189. Oxford University Press, Oxford, UK.

Stoletzki N, Schierwater B (2005) Genetic and color morph differentiation in the Caribbean sea anemone Condylactis gigantea. Marine Biology, 147, 747-754.

Sugumaran M (2002) Comparative biochemistry of eumelanogenesis and the protective roles of phenoloxidase and melanin in insects. Pigment Cell Research, 15, $2-9$

Tanaka K (2007) Thermal biology of a colour-dimorphic snake, Elaphe quadrivirgata, in a montane forest: do melanistic snakes enjoy thermal advantages? Biological Journal of the Linnean Society, 92, 309-322.

Thomas CD, Lennon JJ (1999) Birds extend their ranges northwards. Nature, 399, 213.

Thompson J, Charpentier A, Bouguet G et al. (2012) Evolution of a genetic polymorphism with climate change in a Mediterranean landscape. Proceedings of the National Academy of Sciences, 110, 2893-2897.

Tuttle EM (2003) Alternative reproductive strategies in the white-throated sparrow: behavioural and genetic evidence. Behavioral Ecology, 14, 425-432.

Van den Brink V, Dreiss AN, Roulin A (2012) Melanin-based colouration predicts natal dispersal in the barn owl Tyto alba. Animal Behaviour, 84, 805-812.

Walsberg GE, Campbell GS, King JR (1978) Animal coat color and radiative heat gain: a re-evaluation. Journal of Comparative Physiology, 126, 211-222.

Walters RJ, Blanckerhorn WU, Berger D (2012) Forecasting extinction risk of ectotherms under climate warming: an evolutionary perspective. Functional Ecology, 26, 1324-1338.

Wilson RJ, Gutièrrez D, Martinez D, Agudo R, Montserrat VJ (2005) Changes to the elevational limits and extent of species ranges associated with climate change Ecology Letters, 8, 1138-1146.

Zink RM, Remsen JV (1986) Evolutionary processes and patterns of geographic variation in birds. Current Ornithology, 4, 1-69. 